\title{
Determination of Pesticide Residues in Sugarcane Honey by QuEChERS and Liquid Chromatography
}

\author{
Maicon R. F. Sampaio, Débora Tomasini, Liziane V. Cardoso, \\ Sergiane S. Caldas and Ednei G. Primel* \\ Programa de Pós Graduação em Química Tecnológica e Ambiental, Escola de Química e Alimentos, \\ Universidade Federal do Rio Grande, Av Itália, km 8, 96201-900 Rio Grande-RS, Brazil
}

Neste trabalho, é descrito um método para determinação dos agrotóxicos 2,4-D, diurom e fipronil em mel de cana-de-açúcar. O método QuEChERS foi empregado para extração e a quantificação foi realizada por cromatografia líquida de alta eficiência acoplada ao detector por arranjo de diodos (HPLC-DAD) e cromatografia líquida acoplada à espectrometria de massas sequencial com fonte de ionização por eletronebulização (LC-ESI-MS/MS). Após a otimização dos parâmetros de extração e determinação dos agrotóxicos, o método foi validado avaliando-se a curva analítica, linearidade, limites de detecção e quantificação, precisão (repetibilidade) e exatidão (recuperação). Devido à ocorrência do efeito de matriz, a quantificação foi realizada com os padrões analíticos preparados no extrato branco da matriz. O método apresentou limites de detecção na faixa de $0,016-0,1 \mathrm{mg} \mathrm{kg}^{-1}$ por HPLC-DAD e de $0,00016-0,0008 \mathrm{mg} \mathrm{kg}^{-1}$ por LC-ESI-MS/MS. O método foi empregado na determinação de agrotóxicos em mel de cana-de-açúcar.

This paper aims at describing a method to determine the pesticides 2,4-D, diuron and fipronil in sugarcane honey. The QuEChERS method was employed for extraction and the quantification was carried out by high performance liquid chromatography coupled with diode array detector (HPLC-DAD) and liquid chromatography-tandem mass spectrometry with electrospray ionization source (LC-ESI-MS/MS). After the optimization of the extraction parameters and the determination of the pesticides, the method was validated by evaluating the analytical curve, linearity, limits of detection and quantification, precision (repeatability) and accuracy (recovery). Due to the occurrence of matrix effect, the quantification was performed using the analytical standards prepared in the blank matrix extract. The method provided limits of detection in the range of $0.016-0.1 \mathrm{mg}$ $\mathrm{kg}^{-1}$ by HPLC-DAD and $0.00016-0.0008 \mathrm{mg} \mathrm{kg}^{-1}$ by LC-ESI-MS/MS. The method was applied to the determination of pesticides in sugarcane honey.

Keywords: pesticides, sugarcane honey, QuEChERS, liquid chromatography

\section{Introduction}

The sugarcane (Saccharum officinarum L.) cultivation is one of the most important agricultural activities in Brazil where its main end products are alcohol, sugar and derived foods. ${ }^{1}$

The demand for food products and fuels has required the use of chemical products, such as pesticides and fertilizers, to guarantee and increase sugarcane production. ${ }^{2,3}$ Environmental and public health problems have been observed in the Brazilian sugarcane production, such as the indiscriminate use of pesticides to control pests and diseases and the burning of extensive areas of sugarcane,

*e-mail: eprimelfurg@gmail.com a procedure widely employed that generates large amounts of particulate material containing high levels of polycyclic aromatic hydrocarbons. ${ }^{4,5}$

Since products originated from sugarcane, such as honey and juice, may contain residues of pesticides, it is important to develop methods to determine pesticides in these products. ${ }^{4}$ In Brazil, two studies about the determination of pesticide residues in sugarcane juice were found. Zuin et al. ${ }^{4}$ used two techniques, stir bar sorptive extraction and membrane-assisted solvent extraction, for the determination of 18 organic contaminants. Residues of atrazine, simazine and ametryne in sugarcane juice samples were detected. In the study developed by Furlani et al. ${ }^{6}$ no pesticide residues were detected (< LOD) among the sugarcane juice samples analysed. The authors employed 
QuEChERS sample preparation and GC-ECD for the determination of 7 pesticides in sugarcane juice. ${ }^{6}$

Food products derived from sugarcane are beneficial to health because they are rich in nutrients and contain natural antioxidants (flavonoids). ${ }^{7}$ Sugarcane honey is the syrupy liquid obtained by evaporation of the sugarcane juice, concentrated until it reaches solids content between 65 and $75 \%$. The necessary temperature to achieve the solids content is $105-110{ }^{\circ} \mathrm{C} .{ }^{8,9}$ The sugarcane honey presents a complex matrix rich in carbohydrates and contains proteins, minerals such as calcium and iron, and vitamins. ${ }^{9}$ Its complexity requires a selective sample preparation because some matrix substances can be co-extracted with the analytes under analysis and interfere in the detection. ${ }^{2}$

Pesticides in foods are usually extracted by liquidliquid extraction (LLE) ${ }^{10}$ matrix solid-phase dispersion (MSPD), ${ }^{11}$ solid-phase microextraction (SPME) ${ }^{12}$ and QuEChERS, which was proposed for the first time by Anastassiades et al. ${ }^{13}$ The last one can be considered a quick, easy, cheap, effective, robust, and safe (QuEChERS) sample treatment method. Essentially, it is based on the extraction of the analytes from the sample matrix with an organic solvent (commonly acetonitrile) followed by the removal of interferences using a clean-up sorbent; then, the pure extracts are finally analyzed by the appropriate analytical technique. ${ }^{13}$ QuEChERS has been extensively used for the determination of pesticides in different matrixes such as fruits, vegetables, honey and juice samples. ${ }^{14-16}$ Liquid chromatography (LC) with several detectors is the favorite approach for polar and thermally labile pesticides. ${ }^{17-20}$

In Brazil, the National Agency of Sanitary Vigilance (Agência Nacional de Vigilância Sanitária - ANVISA) is responsible for the establishment of the maximum residue limits (MRL's) for various foods marketed in the country. ${ }^{2}$ In the case of sugarcane, ANVISA establishes a MRL for some pesticides. However, there is no specific legislation for foods derived from sugarcane.

The pesticides under analysis are the herbicides 2,4-D (phenoxycarboxylic acid) and diuron (urea) and the insecticide fipronil (pyrazole). The action mode of them is selective systemic, systemic and moderately systemic, respectively. These pesticides are often used in the sugarcane cultivation in Rio Grande do Sul State and they are active ingredients authorized for use on sugarcane by ANVISA and the Ministry of Agriculture. ${ }^{21}$

This paper reports the validation of a simple, relatively fast, and efficient method using extraction with acetonitrile and phase partition with magnesium sulfate followed by HPLC-DAD and LC-ESI-MS/MS for the determination of 2,4-D, diuron and fipronil in sugarcane honey. This method was used for the determination of pesticide residues in sugarcane honey bought in local supermarkets.

\section{Experimental}

\section{Reagents and chemicals}

Diuron (3-(3,4-dichlorophenyl)-1,1-dimethylurea), 2,4-D (2,4-dichlorophenoxyacetic acid) and fipronil (5-amino-1-(2,6-dichloro- $\alpha, \alpha, \alpha$-trifluoro-p-tolyl)-4trifluoromethylsulfinylpyrazole-3-carbonitrile) analytical standards (purity $>99.0 \%$ ) were supplied by Sigma Aldrich (São Paulo, Brazil). HPLC grade methanol and acetonitrile were supplied by Mallinckrodt (Phillisburg, NJ, USA), formic acid (98.0\%) and phosphoric acid (85.0\%) of analytical grade, by Merck (Darmstadt, Germany), PSA sorbent (primary secondary amine), $40 \mu \mathrm{m}$ bondesil by Varian (Palo Alto, CA, USA) and magnesium sulfate anhydrous $(99.8 \%)$ by J.T. Baker (Tokyo, Japan). Water was purified by Direct-Q UV3 ${ }^{\circledR}$ (resistivity $18.2 \mathrm{M} \Omega \mathrm{cm}$,) water purification system (Millipore, Bedford, MA, USA).

\section{Preparation of solutions}

Individual pesticide stock solutions containing $1000 \mathrm{mg} \mathrm{L}^{-1}$ of the target pesticides were prepared in methanol and stored at $-18{ }^{\circ} \mathrm{C}$. Intermediate working standards mixtures in methanol, containing $100 \mathrm{mg} \mathrm{L}^{-1}$ for each pesticide were prepared and used to prepare the working standard solutions; these ones were used for spiking samples and for preparing the analytical curves in methanol and in the blank matrix extract.

\section{Chromatographic methods}

\section{HPLC-DAD}

To determine the optimum conditions of separation a column Thermo BDS Hyperclone C18 $5 \mu \mathrm{m}(250 \times 4.6 \mathrm{~mm})$ and different mobile phases comprising several combinations of methanol and purified water were tested to provide better separation. The $\mathrm{pH}$ of the purified water was adjusted by a Hanna pH 21, pHmeter. The mobile phases were degassed for $30 \mathrm{~min}$ in an ultrasonic bath before use. Separation was performed using an HPLC with a Waters 600 pump model, associated with a Waters 2996 photodiode array detector, Rheodyne $20 \mu \mathrm{L}$ loop injector, connected to Empower PDA software for data acquisition. The analytical column was conditioned by passing the mobile phase through it for $30 \mathrm{~min}$ at a flow rate of $1.0 \mathrm{~mL} \mathrm{~min}^{-1}$ and the analytical column was operated at room temperature. The flow rate 
was set to $1.0 \mathrm{~mL} \mathrm{~min}^{-1}$ and quantification was carried out with DAD detection at $220.0 \mathrm{~nm}$ (for 2,4-D and fipronil) and at $250.0 \mathrm{~nm}$ for diuron.

The identification of the pesticides in the samples was accomplished on the basis of their retention times and by comparison between the DAD spectrum of the pesticides in the standard solutions and the DAD spectrum of the detected peak in the sample.

\section{LC-ESI-MS/MS}

Liquid chromatography was performed in a Waters Alliance 2695 Separations Module fitted with an autosampler, a membrane degasser and a quaternary pump. Mass spectrometry was performed in a Micromass Quattro Micro API with an ESI interface. The LC separation was carried out in an XTerra analytical column C18 $3.5 \mu \mathrm{m}$ $(50 \times 3 \mathrm{~mm})$ (Waters, Milford, MA, USA). Analytical instrument control, data acquisition and treatment were performed by software Masslynx version 4.1, 2005 (Waters, Milford, MA, USA).

A sample volume of $10 \mu \mathrm{L}$ was injected by an autosampler. Ionization of the pesticides was studied by using ESI interface in the positive (PI) and negative (NI) ionization modes. The mass spectrometer was operated in scan and MRM (multiple reaction monitoring) modes. Typical interface conditions were optimized for maximum intensity of the precursor ions as follows: capillary voltage $3.5 \mathrm{kV}$; nebulizer and desolvation (drying gas) flows were set at 550 and $50 \mathrm{~L} \mathrm{~h}^{-1}$, respectively; source block and desolvation temperatures were 100 and $450^{\circ} \mathrm{C}$, respectively. Nitrogen was used as nebulizing, desolvation and cone gas, and argon was used as collision gas.

\section{Optimization of the QuEChERS sample preparation method}

The tests of optimization of the extraction procedure included the sample mass selection, the solvent of extraction and the evaluation of the clean-up in the extraction efficiency. All optimization procedures were performed in triplicate and injected three times $(n=9)$ and the determination were carried out in HPLC-DAD.

\section{Mass of sample}

Different masses of sample were tested $(0.5,1.0,2.5,5.0$ and $10.0 \mathrm{~g}$ ). The weighed sample was spiked with a known concentration of the mixture of pesticides. After weighting, $10 \mathrm{~mL}$ of ultrapure water were added to facilite the sample homogenization and phase partition. The aqueous samples was acidified to $\mathrm{pH} 2.0$ with phosphoric acid $1: 1 \mathrm{v} / \mathrm{v}$, by vortex agitation. After, $4 \mathrm{~g}$ anhydrous $\mathrm{MgSO}_{4}$ were added and the aqueous sample was extracted with $5 \mathrm{~mL}$ of acetonitrile, followed by centrifugation at $5000 \mathrm{rpm}$ for $2 \mathrm{~min}$ according to Barakat et al. ${ }^{15}$

The use of $5 \mathrm{~mL}$ of acetonitrile was a modification, since the original QuEChERS method developed by Anastassiades et al. ${ }^{13}$ employs $10 \mathrm{~g}$ sample to $10 \mathrm{~mL}$ of solvent.

\section{Extraction solvent}

Four solvents were tested: methanol, ethyl acetate, acetone and acetonitrile. The selection of extraction solvent was carried out with $10 \mathrm{~g}$ of sample, $5 \mathrm{~mL}$ of each solvent and centrifuged at $5000 \mathrm{rpm}$ for $2 \mathrm{~min}$.

\section{Clean-up}

For the clean-up tests the experimental conditions were: $10.0 \mathrm{~g}$ sample acidified to $\mathrm{pH} 2.0$ with phosphoric acid $1: 1 \mathrm{v} / \mathrm{v}$ and $5 \mathrm{~mL}$ acetonitrile solvent.

For the clean-up step, $1.0 \mathrm{~mL}$ upper layer was added to one tube containing $0.025 \mathrm{~g}$ PSA and $0.15 \mathrm{~g}$ anhydrous magnesium sulfate and centrifuged at $5000 \mathrm{rpm}$ during $2 \mathrm{~min}$. An aliquot of the $0.5 \mathrm{~mL}$ extract was collected and $20.0 \mu \mathrm{L}$ was injected into the chromatographic system.

\section{Optimized QuEChERS method}

The $10.0 \mathrm{~g}$ mass of sample, weighed in a $50 \mathrm{~mL}$ PFTE tube, was fortified by the addition of an established volume of solution with $10.0 \mathrm{mg} \mathrm{L}^{-1}$ of each pesticide, resulting in three levels of fortification $0.25,0.5$ and $1.0 \mathrm{mg} \mathrm{kg}^{-1}$ by HPLC-DAD and $0.0025,0.005$ and $0.05 \mathrm{mg} \mathrm{kg}^{-1}$ by LC-ESI-MS/MS. After $1 \mathrm{~h}, 10.0 \mathrm{~mL}$ purified water were added and the mixture was stirred in vortex for homogenization. The homogeneous sample was acidified at $\mathrm{pH} 2.0$ with phosphoric acid $1: 1(\mathrm{v} / \mathrm{v})$. After that, $5.0 \mathrm{~mL}$ acetonitrile and $4.0 \mathrm{~g}$ anhydrous magnesium sulfate were added and vortexed for $1 \mathrm{~min}$ followed by centrifugation at $5000 \mathrm{rpm}$ for $2 \mathrm{~min}$. After that, $1.0 \mathrm{~mL}$ upper layer was removed with a syringe and $20.0 \mu \mathrm{L}$ injected into the HPLC-DAD and $10.0 \mu \mathrm{L}$ into the LC-ESI-MS/MS.

\section{Influence of temperature}

The sugarcane honey is derived from the sugarcane juice which goes through a heating process at $105^{\circ} \mathrm{C} .{ }^{9}$ To assess the influence of temperature in the concentration of the sample pesticides, the sample spiked with the analytes was heated at $105{ }^{\circ} \mathrm{C}$ for $1 \mathrm{~h}$. After cooled to room temperature $\left(20{ }^{\circ} \mathrm{C}\right)$ it was subjected to the extraction process.

The results of the extraction of the sample that was undergone to the heat were compared with the results obtained for the extracted sample that was not previously heated. 
Thus, it is possible to evaluate the influence of temperature in the stability of three pesticides in this condition.

This procedure do not have a purpose to simulate the actual process of obtaining the sugarcane honey, but verify if the procedure employed to obtain the sugarcane honey influence in the pesticides concentration.

\section{Method validation}

To ensure that a new analytical method generates reliable and interpretable information about the sample, it must undergo an assessment called validation. The concepts of validation keep evolving and are constantly under investigation by regulating agencies. ${ }^{22}$ Once the best conditions for the analysis of the pesticides were defined, the validation of the method was carried out according to parameters described below.

\section{Analytical curves and linearity}

The analytical curves and linearity of the detector response for the pesticides were evaluated by injecting a total of six calibration working standard solutions into the concentration levels $0.05,0.1,0.625,1.25,2.5$ and $5.0 \mathrm{mg} \mathrm{L}^{-1}$ in HPLC-DAD and 0.0005, 0.001, 0.005, 0.01, $0.05,0.1,0.5$ and $1.0 \mathrm{mg} \mathrm{L}^{-1}$ in LC-ESI-MS/MS with three replicate injections per concentration. Similarly, the analytical curves were built in the blank matrix extract.

Limit of detection (LOD) and quantification (LOQ)

In this study, LOD and LOQ were determined considering the LOD as 3 times the baseline noise and the LOQ the concentration that produced a signal 10 times the baseline noise, in a time close to the retention time of each analyte. ${ }^{22,23}$

\section{Precision and accuracy}

The precision in terms of repeatability was obtained by carrying out the extraction and analysis of fortified samples. Each spike level was extracted in three replicates and each extract injected three times.

The accuracy of the analytical method was evaluated in terms of recovery. Analyses were carried out in three replicates of "blank" sugarcane honey samples spiked at three different levels by HPLC-DAD and by LC-ESI-MS/MS. The recovery was calculated by the area ratio obtained in fortified samples and the areas of standards solutions diluted with the blank matrix extract, according to Kruve et al. ${ }^{24}$

\section{Matrix effect}

The matrix effect is generally recognized as suppression or enhancement of the analytical signal due to co-eluting matrix components. ${ }^{25}$ Depending on the complexity of the matrix, the analyte signal obtained in solvent may be different from the one obtained in the blank matrix extract. ${ }^{26}$

The study of matrix effect (ME) was performed according to Kruve $e t$ al. ${ }^{24}$ The area of the standard solution diluted with the blank matrix extract was compared to the area of the standard solution diluted in solvent. The results of ME equal to $100 \%$ indicate there is no matrix effect, while values higher or lower than $100 \%$ indicate suppression or enrichment of the ionization by the matrix components. ${ }^{24}$

Another way to evaluate the matrix effect was through the comparison of the slopes obtained in the calibration with matrix matched-standards with those obtained with calibration with standards diluted in the solvent. ${ }^{27}$

\section{Results and Discussion}

\section{Chromatographic analysis}

\section{Optimization of HPLC-DAD chromatographic parameters}

Since run time is very important, we tried to find a shorter run time with good separation and identification of the pesticides. Several mixtures of mobile phases were tested in the isocratic elution mode. The mixtures methanol:water $\mathrm{pH} 3.0(50: 50 \mathrm{v} / \mathrm{v}$ and $60: 40 \mathrm{v} / \mathrm{v})$ were not satisfactory because the run time was too long, and in this case the pesticide fipronil was detected in a time longer than $20 \mathrm{~min}$. When mixture methanol:water pH $3.0(65: 35 \mathrm{v} / \mathrm{v})$ was used, the run time was shorter and the substances were detected in $18 \mathrm{~min}$ but the resolution was unsatisfactory.

The use of gradient elution of the mobile phase was satisfactory, and good peaks within acceptable retention time were obtained. The effective separation of the peaks in the chromatogram was achieved when the mobile phase initial composition was methanol:water pH $3.0(65: 35, \mathrm{v} / \mathrm{v})$, acidified with $\mathrm{H}_{3} \mathrm{PO}_{4} 1: 1(\mathrm{v} / \mathrm{v})$, flow rate of $1.0 \mathrm{~mL} \mathrm{~min}^{-1}$ increasing to methanol:water $\mathrm{pH} 3.0(80: 20, \mathrm{v} / \mathrm{v})$, flow

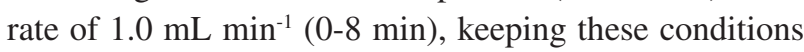
for $4 \mathrm{~min}$, coming back to the initial composition in $1 \mathrm{~min}$ and remaining under these conditions until $20 \mathrm{~min}$. The optimum conditions of separation were obtained with the column Hyperclone BDS C18 $5 \mu \mathrm{m}(250 \times 4.6 \mathrm{~mm})$. The chromatogram of the blank matrix extract and separation of the pesticides in solvent and in blank matrix extract is shown in Figure 1.

The water $\mathrm{pH}$ adjusted to 3.0 provided better separation for the compound 2,4-D because, in this acidic conditions, 

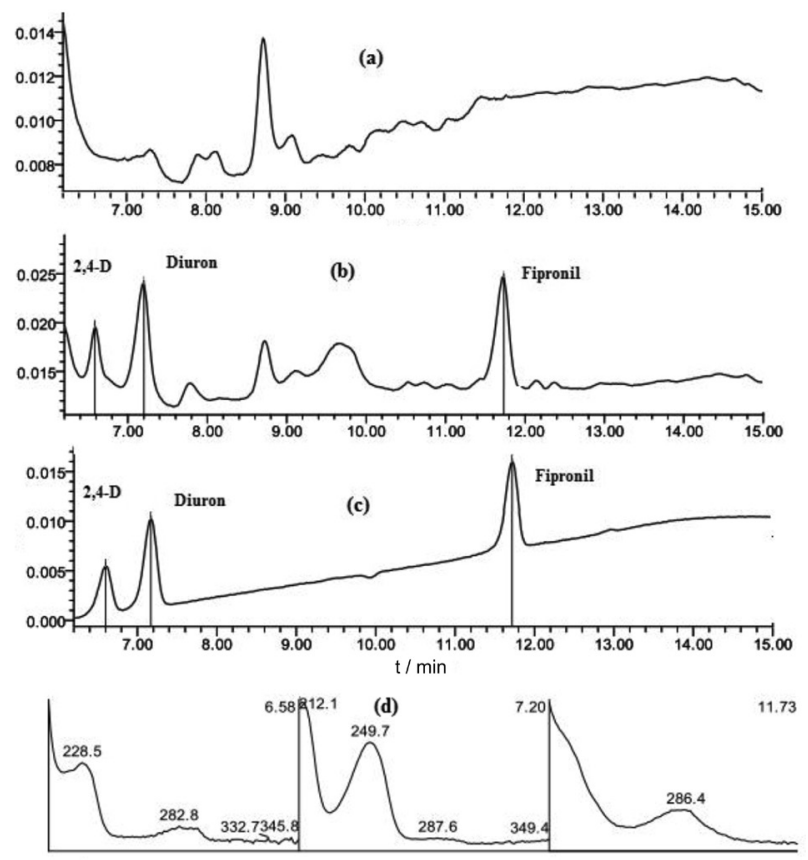

Figure 1. Chromatogram of blank matrix extract (a), mixture of pesticides diluted in the blank matrix extract in the concentration level $1 \mathrm{mg} \mathrm{kg}^{-1}$ (b) and in solvent (c), at $220.0 \mathrm{~nm}$ with their identification spectra (d), in the best chromatographic conditions.

the molecular form of the compound has better interaction with the column, since 2,4-D is an organic acid with $\mathrm{pKa}$ of 2.6 and high water solubility. ${ }^{28}$ When the water was not acidified, 2,4-D co-eluted with the solvent peak and there was unsatisfactory separation.

\section{LC-ESI-MS/MS parameters}

The LC-ESI-MS/MS technique is proposed in this study as a viable alternative to determine the pesticides in sugarcane honey. The mobile phase was methanol:water acidified with $0.1 \%$ formic acid $(65: 35, \mathrm{v} / \mathrm{v})$, at a flow rate of $0.2 \mathrm{~mL} \mathrm{~min}^{-1}$; it enabled the analysis of all analytes in $8.0 \mathrm{~min}$. Formic acid proved to be efficient for ionizing the pesticides under investigation. The chromatograms were recorded in full scan mode with the ESI interface in the positive and negative ionization modes. The scan range was $m / z 100-450$. The results are shown in Table 1. Two of the selected pesticides (2,4-D and fipronil) showed more efficient ionization in the NI mode, whereas diuron showed preferential ionization in the PI mode. The MRM analysis introduces high specificity as it is based on the detection of both a parent ion and one of its known fragments. For each compound, we selected the optimum collision energies with the aim of getting two characteristic MRM transitions with the best signal intensity. We chose the MRM transition with the best signal intensity for quantification. The main advantage of the method was the use of MS/MS because it provides a high level of confidence to identify the target pesticides. The monitoring of the products of secondary fragmentation allows a much greater discrimination of interfering matrix than the use of the products of primary fragmentation (MS). In fact, this technique allows the analysis of pesticides even in the presence of interferences. The controlled fragmentation of MS is an essential tool for the reliable identification of the analyte under investigation with higher selectivity. In addition, this fragmentation generates cleaner signals, improving the signal to noise ratio and thus reducing the limits of detection and quantification. ${ }^{2}$

\section{Optimization of QuEChERS method}

The results of the optimization of QuEChERS method were obtained by injections into the HPLC-DAD and, after optimization, the validation was carried out in both HPLCDAD and LC-ESI-MS/MS.

\section{Mass of sample}

Good results (recoveries of 70-120\%) were obtained using different masses of sample. Ten grams of material extracted with $5.0 \mathrm{~mL}$ of acetonitrile was chosen in order to have a ratio $2: 1(\mathrm{~m} / \mathrm{v})$ sample:solvent and thereby allow the pre concentration of the analytes by decreasing the levels of fortification, since the original method is only for extraction. Results are shown in Figure 2a.

\section{Selection of extraction solvent}

When using methanol, a biphasic system was not observed. Moreover, the supernatant contained undissolved

Table 1. Results of the mass spectrometer conditions for the simultaneous analysis of pesticides (dwell time $0.3 \mathrm{~s}$ )

\begin{tabular}{|c|c|c|c|c|c|c|c|}
\hline Pesticide & $\begin{array}{l}\text { Ionization } \\
\text { mode }\end{array}$ & $\begin{array}{c}\text { Molecular } \\
\text { weight }\end{array}$ & $\begin{array}{l}\text { Precursor } \\
\text { ion / }(\mathrm{m} / \mathrm{z})\end{array}$ & $\begin{array}{l}\text { Product } \\
\text { ion / }(\mathrm{m} / \mathrm{z})\end{array}$ & $\begin{array}{c}\text { Cone } \\
\text { voltage / V }\end{array}$ & $\begin{array}{c}\text { Collision } \\
\text { energy / eV }\end{array}$ & $\begin{array}{l}\text { Retention } \\
\text { time / min }\end{array}$ \\
\hline $2,4-\mathrm{D}$ & ESI- & 221.0 & 219 & $\begin{array}{l}219 \rightarrow 161 \\
219 \rightarrow 89\end{array}$ & $\begin{array}{l}15 \\
15\end{array}$ & $\begin{array}{c}20^{\mathrm{a}} \\
30\end{array}$ & 3.2 \\
\hline Fipronil & ESI- & 437.0 & 435 & $\begin{array}{l}435 \rightarrow 250 \\
435 \rightarrow 330\end{array}$ & $\begin{array}{l}15 \\
26\end{array}$ & $\begin{array}{l}30^{\mathrm{a}} \\
25\end{array}$ & 7.6 \\
\hline Diuron & ESI+ & 233.0 & 233 & $\begin{array}{l}233 \rightarrow 72 \\
233 \rightarrow 160\end{array}$ & $\begin{array}{l}20 \\
25\end{array}$ & $\begin{array}{l}28^{\mathrm{a}} \\
28\end{array}$ & 3.8 \\
\hline
\end{tabular}

Indicates the most intense product ion, selected for quantification. 
(a)

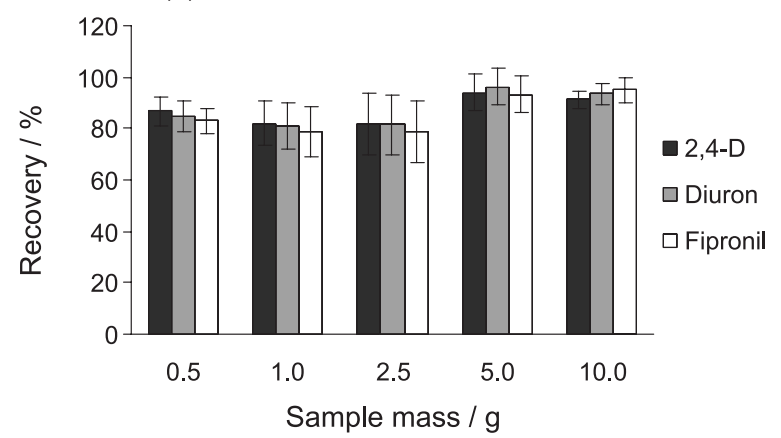

(b)

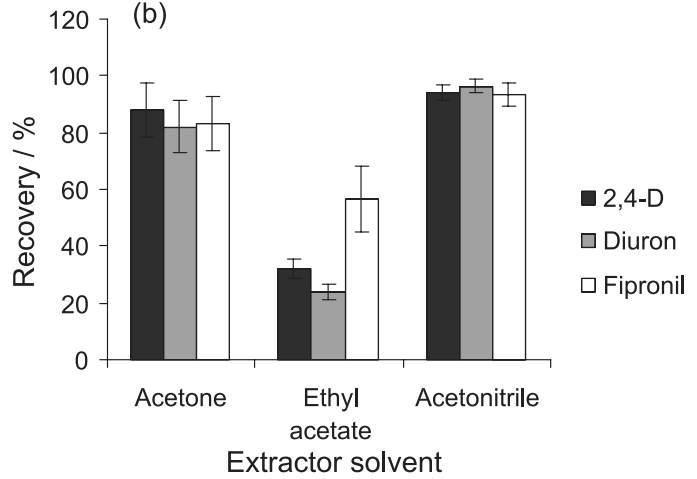

Figure 2. (a) Effects of different sample mass and (b) different extraction solvents in recovery of pesticides. Error bars indicate RSD values $(\%)(n=9)$.

solids. Ethyl acetate presented lower percentages of recovery for polar pesticides such as 2,4-D and diuron. A problem with ethyl acetate is that some of the most polar pesticides do not readily partition into the ethyl acetate phase. To increase recoveries of polar pesticides, large amounts of sodium sulfate are usually added in extraction procedures. ${ }^{29,30}$

With the use of acetone, a biphasic system was observed, but the volume of the extract supernatant was higher than the volume of the added solvent. Using acetonitrile, acceptable recoveries for all pesticides were obtained. Furthermore, acetonitrile does not extract much lipophilic material, e.g., waxes, fat, and lipophilic pigment. ${ }^{31}$ In practice, a triphasic system was observed, because between the organic and aqueous phases, an interface with lipophilic material was formed. That is, the use of acetonitrile provided a lower number of coextractives. ${ }^{31}$ Therefore, acetonitrile was chosen as the extraction solvent for the technique, using $5.0 \mathrm{~mL}$ solvent for a $10.0 \mathrm{~g}$ sample, resulting in a ratio of $1.0 \mathrm{~g}$ sample with $0.5 \mathrm{~mL}$ solvent, without involving the evaporation step. Results are shown in Figure 2b.

\section{Clean-up}

The clean-up step reduced the pigment of the extract, probably because the PSA retained matrix substances that cause pigmentation to the extract. However lower recoveries (35.4\% with $\mathrm{RSD}<5.11 \%$ ) were observed for $2,4-\mathrm{D}$, according to Figure 3, probably due to the interaction of PSA with 2,4-D, a pesticide of acid character. In study developed by Amakura et al. ${ }^{32}$ the PSA was used for retention of phenolic acids in fuit juices. ${ }^{32}$ The polar organic acids, sugars and fatty acids are retained on the PSA, while the C18 was not used in this work being more suitable for samples containing fat levels $\geq 2 \%$, for example, rice, barley and wheat. ${ }^{29}$

Studies have cited that the basic PSA can interact with acid pesticides. In 2010, Niell et al. ${ }^{33}$ analyzed nine multiclass herbicides in polished rice using an acetate buffered modification of QuEChERS without the PSA clean- up. The PSA was avoided because acidic herbicides could be retained during the clean-up step. ${ }^{33}$

Pareja et al. ${ }^{34}$ developed a sample preparation procedure for analysis of 16 herbicides commonly applied in rice crops using LC-QqQ/MS. The authors mention that the PSA contains primary and secondary amino groups that remove acidic compounds from the extract. ${ }^{34}$

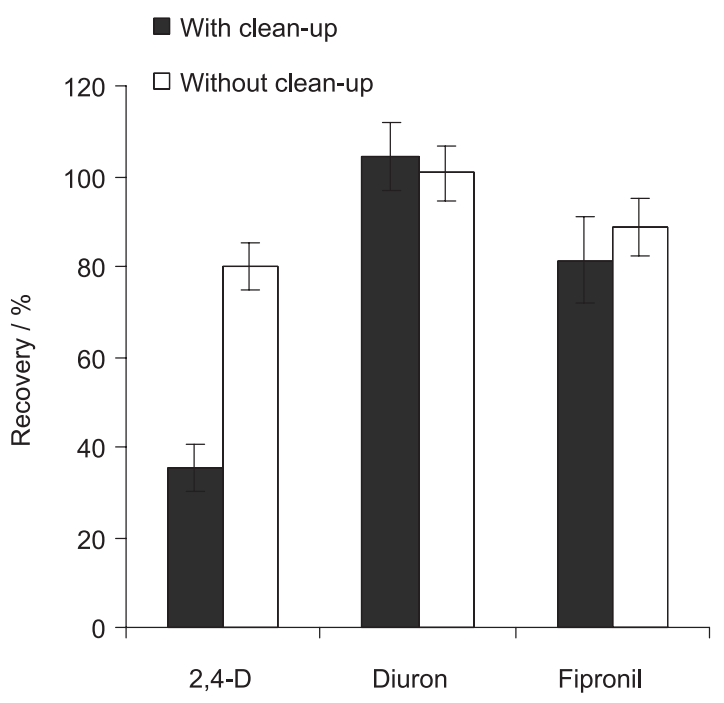

Figure 3. Evaluation of the clean-up step. Error bars indicate RSD values $(\%)(\mathrm{n}=9)$.

Influence of temperature

After heating the sample at $105^{\circ} \mathrm{C}$, recoveries changed slightly (Figure 4). The experiment indicated that even after heating the pesticides are detected and quantified in the sample, thus justifying the development of methods to analyze pesticides in the processed foods.

\section{Method validation}

Linear relationships among the ratios of the peak area signals and the corresponding concentrations were observed. 


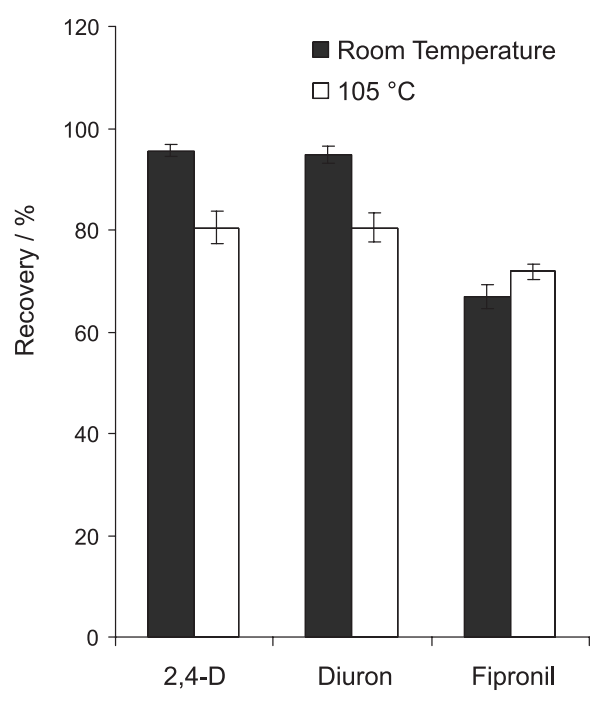

Figure 4. Recoveries (\%) after heating the spiked sample at $105^{\circ} \mathrm{C}$ and for the spiked sample that was extracted without heating. Error bars indicate RSD values $(\%)(\mathrm{n}=9)$.

The parameters of the analytical curves with the correlation coefficients are shown in Table 2, and Table 3 shows the calibration data of linear regression of LC-ESI-MS/MS. The values of the correlation coefficients (r) agree with the values recommended by ANVISA and Instituto Nacional de Metrologia, Normalização e Qualidade Industrial (INMETRO). ANVISA recommends a correlation coefficient of at least 0.99 and INMETRO suggests values above $0.90 .^{35,36}$

When comparing the response with the baseline noise, the LOD's for the mixture of pesticides were between 0.016 and $0.1 \mathrm{mg} \mathrm{kg}^{-1}$ and the LOQ's were between 0.05 and $0.3125 \mathrm{mg} \mathrm{kg}^{-1}$ by HPLC-DAD. By LC-ESI-MS/MS, the LOD's were between 0.00016 and $0.0008 \mathrm{mg} \mathrm{kg}^{-1}$ and the LOQ's were between 0.0005 and $0.0025 \mathrm{mg} \mathrm{kg}^{-1}$.
Recoveries for all pesticides resulted in values ranging between $63.2 \%$ and $114.7 \%$, with RSD lower than $11.04 \%$ by HPLC-DAD. By LC-ESI-MS/MS, recoveries for all pesticides resulted in values ranging between $90.4 \%$ and $120.0 \%$, with RSD from $2.5 \%$ to $20.0 \%$. The acceptable ranges of recovery for trace residue analysis are usually between 70 and $120 \%$, with RSD $\pm 20 \%{ }^{29,35}$

Table 4 summarizes the results of recovery and precision of the method under study and its satisfactory values.

Matrix effect

By HPLC-DAD the matrix effect was not significant. By LC-ESI-MS/MS, the compound 2,4-D presented ME (matrix effect) of $46.6 \%$, indicating that the compound suffers ionization suppression, the herbicide diuron presented ME of $135.1 \%$ indicating ionization enrichment by the matrix components. For fipronil the ME was $91.6 \%$, presented lower ME, because the results of ME equal to $100 \%$ indicate there is no matrix effect.

By LC-ESI-MS/MS, only the signal of interest is registered, leaving out the information about the occurrence of all the other substances. This fact gives the illusion that the other substances that co-elute with the analyte do not interfere with the results. However, other substances - although invisible in the LC-ESI-MS/MS signal - may and very often interfere, causing suppression or enhancement of ionization in the ESI source before mass-spectrometric detection..$^{24,25}$

To compensate the matrix effect and not to produce overestimated or underestimated results, for accuracy, all recoveries were calculated using the standard prepared in the blank matrix extract. ${ }^{24}$

The evaluation of the slopes obtained in the calibration with matrix matched-standards were compared with those

Table 2. Analytical characteristics of HPLC-DAD and LC-ESI-MS/MS

\begin{tabular}{|c|c|c|c|c|c|c|}
\hline \multirow{2}{*}{ Pesticide } & \multicolumn{2}{|c|}{ Method linearity / $\left(\mathrm{mg} \mathrm{L}^{-1}\right)$} & \multicolumn{2}{|r|}{$\mathrm{r}$} & \multicolumn{2}{|c|}{ Method LOQ / $\left(\mathrm{mg} \mathrm{kg}^{-1}\right)$} \\
\hline & HPLC-DAD & LC-ESI-MS/MS & HPLC-DAD & LC-ESI-MS/MS & HPLC-DAD & LC-ESI-MS/MS \\
\hline $2,4-\mathrm{D}$ & $0.625-5.0$ & $0.005-1.0$ & 0.9990 & 0.9994 & 0.3125 & 0.0025 \\
\hline Diuron & $0.1-5.0$ & $0.005-1.0$ & 0.9992 & 0.9999 & 0.05 & 0.0025 \\
\hline Fipronil & $0.2-5.0$ & $0.001-1.0$ & 0.9993 & 0.9981 & 0.1 & 0.0005 \\
\hline
\end{tabular}

Table 3. Calibration data of LC-ESI-MS/MS and matrix effect for comparison of slopes

\begin{tabular}{|c|c|c|c|c|c|c|}
\hline \multirow[t]{2}{*}{ Pesticides } & \multicolumn{2}{|c|}{$\begin{array}{c}\text { Equation }(\mathrm{y}=\mathrm{ax}+\mathrm{b})^{\mathrm{a}} \\
\text { solvent-based standards }\end{array}$} & \multicolumn{2}{|c|}{$\begin{array}{c}\text { Equation }(\mathrm{y}=\mathrm{ax}+\mathrm{b})^{\mathrm{a}} \\
\text { matrix-matched standards }\end{array}$} & \multirow{2}{*}{\multicolumn{2}{|c|}{ Matrix effect }} \\
\hline & $\mathrm{a}$ & $\mathrm{b}$ & $\mathrm{a}$ & $\mathrm{b}$ & & \\
\hline $2,4-\mathrm{D}$ & 45027 & -360 & 21302 & -110 & 0.47 & Signal suppression \\
\hline Diuron & 51178 & -750 & 70481 & +1044 & 1.37 & Signal enrichment \\
\hline Fipronil & 90227 & +1240 & 83004 & +2545 & 0.91 & Low matrix effect \\
\hline
\end{tabular}

${ }^{a} \mathrm{y}=$ peak area, $\mathrm{a}=$ slope, $\mathrm{x}=$ concentration, and $\mathrm{b}=$ intercept. ${ }^{\mathrm{b}}$ Matrix effects are expressed as the ratio between the calibration curve slopes of matrixmatched standards and solvent-based standards. 
Table 4. Recovery $(\mathrm{R} \%)$ and repeatability $\left(\mathrm{RSD}_{\mathrm{r}}\right)$ by HPLC-DAD and by LC-ESI-MS/MS methods for the mixture of 2,4-D, diuron and fipronil in spiked sugarcane honey

\begin{tabular}{|c|c|c|c|c|c|c|}
\hline \multirow[t]{2}{*}{ Pesticides } & \multicolumn{3}{|c|}{ HPLC-DAD } & \multicolumn{3}{|c|}{ LC-ESI-MS/MS } \\
\hline & Spike level / $\left(\mathrm{mg} \mathrm{kg}^{-1}\right)$ & $\mathrm{R} / \%$ & $\mathrm{RSD}_{\mathrm{r}} / \%$ & Spike level / $\left(\mathrm{mg} \mathrm{kg}^{-1}\right)$ & $\mathrm{R} / \%$ & $\mathrm{RSD}_{\mathrm{r}} / \%$ \\
\hline \multirow[t]{3}{*}{$2,4-\mathrm{D}$} & 0.25 & - & - & 0.0025 & 90.4 & 5.3 \\
\hline & 0.5 & 63.3 & 5.7 & 0.005 & 118.6 & 18.9 \\
\hline & 1.0 & 88.4 & 10.0 & 0.05 & 91.2 & 10.4 \\
\hline \multirow[t]{3}{*}{ Diuron } & 0.25 & 95.1 & 7.9 & 0.0025 & 93.3 & 3.1 \\
\hline & 0.5 & 114.7 & 4.4 & 0.005 & 120.0 & 13.6 \\
\hline & 1.0 & 103,1 & 8.5 & 0.05 & 95.9 & 8.1 \\
\hline \multirow[t]{3}{*}{ Fipronil } & 0.25 & 84.8 & 5.8 & 0.0025 & 93.3 & 2.5 \\
\hline & 0.5 & 87.9 & 6.6 & 0.005 & 119.1 & 20.0 \\
\hline & 1.0 & 95.3 & 11.0 & 0.05 & 91.3 & 4.0 \\
\hline
\end{tabular}

$\mathrm{n}=9$.

obtained with solvents standards. Table 3 also shows slope ratio matrix/solvent for each compound and matrix effect was observed for most of the selected compounds. For the 2,4-D signal suppression was noted, to diuron signal enrichment was observed, however to fipronil matrix effect was not pronounced. Romero-González et al. ${ }^{27}$ developed the method using modified QuEChERS-based avoiding any clean-up step prior the determination by ultra-high performance liquid chromatography/tandem quadrupole mass spectrometry (UHPLC-MS/MS) to determine pesticides, biopesticides and mycotoxins from organic products and in this study the matrix effects are expressed as the ratio between the calibration curve slopes of matrixmatched standards and solvent-based standards, where matrix effect values close to 1.0 indicate that the curves are very close and there is not or little matrix effect. ${ }^{27}$

\section{HPLC-DAD and LC-ESI-MS/MS methods}

The validation of QuEChERS method was carried out using HPLC-DAD and LC-ESI-MS/MS. The UV detector, specifically, the DAD has special features such as the screening of the wavelength of maximum absorbance of each compound, enhancing the detectability and sensitivity. Besides, the determination of the purity of the peak provides extra data to the analyst so that he knows that there are no substances eluting in the same retention time of analyte..$^{37,38}$

With HPLC-DAD, the method allows the detection of pesticides at levels of $0.016-0.1 \mathrm{mg} \mathrm{kg}^{-1}$. Since there are no MRL's established for derivatives of sugarcane, and using the reference values set for the sugarcane, which are $0.1 \mathrm{mg} \mathrm{kg}^{-1}$ for 2,4-D and diuron and $0.03 \mathrm{mg} \mathrm{kg}^{-1}$ for fipronil, by both HPLC-DAD and LC-ESI-MS/MS, we can detect pesticides at the levels set for sugarcane.

The method, which used QuEChERS and LC-ESI-MS/ MS, showed the advantage of sensitivity to quantify the compound at levels below the maximum residue limits and lower run time than the HPLC-DAD. The mass detector in tandem coupled with chromatography allows detection of pesticides in low concentration in complex matrices, since it enables the increase of detectability, reduces spectral interference of endogenous matrix substances, and increases the amount of structural information. With the MRM mode of operation, the mass analyzer is set to observe only the ions of interest, increasing reliability of the results; consequently, the limits of quantification are lower than in HPLC-DAD. ${ }^{39}$

\section{Applicability of the method}

The applicability of the method was accomplished through 3 levels of spiked samples of sugarcane honey. Moreover, the validated method was applied to the analysis of two samples from two cities in Rio Grande do Sul State, purchased in local supermarkets. No pesticides were detected in the analyzed samples. However, the monitoring of pesticide residues in foods must be constant. It is important to assure good farming practices and adequate hygiene of raw material during processing.

\section{Conclusions}

The proposed method offers good accuracy and precision to determine pesticide residues in sugarcane honey. The assessment of the matrix effect showed matrix effect on quantification of the pesticides by LC-ESI-MS/MS, and all recoveries were calculated using the standard prepared in the blank matrix extract. The proposed methodology is rapid and selective, with a simple sample preparation procedure that could be used for the detection and quantification of pesticide residues in sugarcane honey samples.

The mass detector in tandem proved to be more sensitive and allowed safe identification and confirmation of the pesticides at low levels of concentration. 


\section{Acknowledgments}

The authors acknowledge CNPq, CAPES and FAPERGS for the financial support.

\section{References}

1. http://www.unica.com.br/dadosCotacao/estatistica/accessed in September, 2011.

2. Jardim, I. C. S. F.; Andrade, J. A.; Queiroz, S. C. N.; Quim. Nova 2009, 32, 996.

3. Tfouni, S. A. V.; Souza, N. G.; Neto, M. B.; Loredo, I. S. D.; Leme, F. M.; Furlani, R. P. Z; Food Chem. 2009, 116, 391.

4. Zuin, V. G.; Schellin, M.; Montero L.; Yariwake, J. H.; Augusto, F.; Popp, P.; J. Chromatogr., A 2006, 1114, 180.

5. Lanchote, V. L.; Bonato, P.S.; Cerdeira, A. L.; Santos, N. A. G.; Carvalho, D.; Gomes, M. A.; Water, Air, Soil Pollut. 2000, $118,329$.

6. Furlani, R. P. Z.; Marcilio, K. M.; Leme, F. M.; Tfouni, S. A. V.; Food Chem. 2011, 126, 1283.

7. Colombo, R.; Yariwake, J. H.; McCullagh, M.; J. Braz. Chem. Soc. 2008, 19, 483.

8. http://www.anvisa.gov.br/legis/resol/12_78_melaco.htm accessed in September, 2011.

9. Silva, F. C.; César, M. A. A.; Silva, C. A. B; Pequenas Indústrias Rurais de Cana-de-Açúcar: Melado, Rapadura e Açúcar Mascavo, Embrapa: Brasília, Brasil, 2003, p.155.

10. Pirard, C.; Widart, J.; Nguyen, B. K.; Deleuze, C.; Heudt, L.; Haubruge, E.; Pauw, E.; Focant, J. F.; J. Chromatogr., A 2007, 1152, 116.

11. Rodrigues, S. A.; Caldas, S. S.; Primel, E. G.; Anal. Chim. Acta 2010, 678, 82.

12. Vázquez, P. P.; Mughari, A. R.; Galera, M. M.; Anal. Chim. Acta 2008, 607, 74 .

13. Anastassiades, M.; Lehotay, S. J.; Stajnbaher, D.; Schenck, F. J.; J. AOAC Int. 2003, 86, 412.

14. Lehotay, S. J.; Son, K. A.; Kwon, H.; Koesukwiwat, U.; Fu, W.; Mastovska, K.; Hoh, E.; Leepipatpiboon, N.; J. Chromatogr., A 2010, 1217, 2548.

15. Barakat, A. A.; Badawy, H. M. A.; Salama, E.; Attallah, E.; Maatook, G.; J. Food Agr. Environ. 2007, $5,97$.

16. Romero-González, R.; Frenich, A. G.; Vidal, J. L. M.; Talanta 2008, 76, 211.

17. Caldas, S. S.; Costa, F. P.; Primel E.G., Anal. Chim. Acta 2010 , $665,55$.

18. Demoliner, A.; Caldas, S. S; Costa, F. P.; Gonçalves, F. F.; Clementin, R. M; Milani, M. R.; Primel, E. G.; J. Braz. Chem. Soc. 2010, 21, 1424.

19. Caldas, S. S.; Demoliner A.; Primel, E. G.; J. Braz. Chem. Soc. 2009, 20, 125.
20. Caldas, S. S.; Demoliner, A.; Costa, F. P.; D’Oca, M. G. M.; Primel, E. G.; J. Braz. Chem. Soc. 2010, 21, 642.

21. http://www4.anvisa.gov.br/AGROSIA/asp/frm_pesquisa_ ingrediente.asp accessed in May 2011.

22. Ribani, M.; Bottoli, C. B. G.; Collins, C. H.; Jardim, I. C. S. F.; Melo, L. F. C.; Quim. Nova 2004, 27, 771.

23. Kurz, M. H. S.; Gonçalves, F. F.; Martel, S.; Adaime, M. B.; Zanella, R.; Machado, S. L. O.; Primel, E. G.; Quim. Nova 2009, 32, 1457.

24. Kruve, A.; Kunnapas, A.; Herodes K.; Leito I.; J. Chromatogr., A 2008, 1187, 58.

25. Matuszewski, B. K.; Constanzer, M. L.; Chavez-Eng, C. M.; Anal. Chem. 2003, 75, 3019.

26. Rodrigues, S. A.; Caldas, S. S.; Furlong, E. B.; Primel, E. G.; Zanella, R.; Quim. Nova 2011, 34, 780.

27. Romero-González, R.; Frenich, A. G.; Vidal, J. L. M.; O. D. Prestes.; Grio, S. L.; J. Chromatogr., A 2011, 1218, 1477.

28. Silva, T. M.; Stets, M. I. ; Mazzetto, A. M.; Andrade, F. D.; Pileggi, S. A. V.; Fávero, P. R.;Cantú, M. D.; Carrilho, E.; Carneiro, P. I. B.; Pileggi, M.; Braz. J. Microbiol. 2007, 38, 522

29. Prestes, O.D.; Friggi,C. A.; Adaime, M. B.; Zanella, R.; Quim. Nova 2009, 32, 1620

30. Holstege, D. M.; Scharberg, D. L.; Tor, E. R.; Hart, L. C.; Galey, F. D.; J. AOAC Int. 1994, 77, 1263.

31. Lehotay, S. J.; Kok, A.; Hiemstra, M.; Bodegraven, P.; J. AOAC Int. 2005, 88, 595

32. Amakura, Y.; Okada, M.; Tsuji, S.; Tonogai, Y.; J. Chromatogr., A 2000, 891, 183.

33. Niell, S.; Pareja, L.; Asteggiante, L. G.; Cesio, M. V.; Heinzen, H.; Food Addit. Contam. A 2010, 27, 206.

34. Pareja, L.; Cesio, V.; Heinzen, H.; Fernández-Alba, A. R.; Talanta 2011, 83, 1613.

35. Agência Nacional de Vigilância Sanitária (ANVISA); Guia para Validação de Métodos Analíticos e Bioanalíticos-Resolução RE No. 899, National Health Surveillance Agency: Brazil, 2003.

36. Instituto Nacional de Metrologia, Normalização e Qualidade Industrial (INMETRO); Orientações sobre Validacão de Métodos de Ensaios Químicos, DOQ-CGCRE-008, INMETRO: Brasil, 2003.

37. Carabias-Martínez, R.; Rodríguez-Gonzalo, E.; HerreroHernández, E.; Hernández-Méndez, J.; Anal. Chim. Acta 2004, 517,71 .

38. Collins, C. H.; Braga, G. L.; Bonato, P.S; Fundamentos de Cromatografia, Ed. Unicamp: Campinas, SP, Brasil, 2006, p. 456.

39. Chiaradia, M. C.; Collins, C. H.; Jardim, I. C. S. F; Quim. Nova 2008, 31, 623.

Submitted: March 17, 2011 Published online: November 8, 2011 